\title{
LA TRADUCCIÓN DE VILLEGAS DE LA ODA I 35 DE HORACIO Y SU RELACIÓN CON LA VERSIÓN DE BARTOLOMÉ LEONARDO DE ARGENSOLA*
}

\author{
Rosa Ma Marina Sáez \\ Universidad de Zaragoza
}

\begin{abstract}
RESUMEN: En este artículo se realiza un análisis traductológico de la versión de la Oda I 35 de Horacio de Esteban Manuel de Villegas al mismo tiempo que se compara con la llevada a cabo por Bartolomé Leonardo de Argensola, poeta con el que mantuvo una estrecha relación amistosa y literaria. A través de dicho análisis se llega a la conclusión de que Villegas presenta un magnífico conocimiento de la lengua latina y de la poesía de Horacio, cuyo contenido respeta en todo momento, así como un estilo de traducción personal, influido en cuestiones de detalle por Fray Luis y Argensola, pero cuya base se halla siempre en el original.
\end{abstract}

ABSTRACT: In this paper is made an traductological analyse of the Esteban Manuel de Villegas' translation of Hor. Carm. I 35, and it is compared to the Bartolome Leonardo de Argensola's one, poet whom he maintained a relation of friendship and literary taste with. Through this analyse is concluded that Villegas had a very good knowledge of Latin and horatian poetry, whose content is respected, and an own translation style, influenced in some details by Fray Luis and Argensola, but ever based on horatian original text.

PALABRAS CLAVE: Villegas; Argensola; Horacio; yraducciones; literatura española; tradición clásica

KEYWORDS: Villegas; Argensola; Horace; translations; Spanish literature; classical tradition

El estudio de las traducciones de textos clásicos en España ha adquirido en los últimos tiempos un auge espectacular, tanto por la abundancia de la producción científica como por la aplicación de nuevos métodos de investigación. Dentro de dichos estudios se ha prestado especial atención a problemas tales como el de la relación entre teoría y práctica de la traducción ${ }^{1}$, o el del valor artístico de las

* Debo agradecer al prof. J. Fernández López, de la Universidad de la Rioja, la lectura del manuscrito, así como las interesantes sugerencias realizadas respecto al mismo.

1. Sobre este problema vid. D. Castro de Castro y F. Moya del Baño, "Traducción filológica y tradición clásica: Mariner y los Idilios de Teócrito", Livius, 10 (1997) pp. 17-29. 
versiones de obras literarias. En ese sentido, es preciso señalar que las traducciones literarias se insertan dentro de una tradición estética determinada, y que en su estudio no sólo resulta necesario analizar la relación con su original sino también con otras versiones de la época².

En esta línea me ha parecido interesante realizar un análisis de la técnica traductológica de una de las versiones de Esteban Manuel de Villegas, concretamente la de la oda I 35 de Horacio ${ }^{3}$, y compararla con otra de Bartolomé Leonardo de Argensola, poeta con el que mantuvo estrechos vínculos ${ }^{4}$. Ambos autores son situados por Rodríguez-Pantoja en lo que denomina "segunda gran etapa humanística" de la traducción ${ }^{5}$, donde priman las versiones de obras literarias, realizadas en ocasiones por autores que buscan mediante esta práctica perfeccionar su estilo.

2. Como indica D. Castro de Castro, "Henri Estienne y la traducción", en A. Ma Aldama et al. (eds.), La Filología Latina hoy. Actualización y perspectivas, (2 vols.), Madrid: SELat., 1999, II pp. 829-835, y "La versión latina de los Idilios de Teócrito por Eobanus Hessus (1530) y su presencia en la de Vicente Mariner (1625)", Myrtia, 14 (1999) pp. 171-185, durante el Siglo de Oro era habitual la consulta de versiones de otros autores.

3. Las traducciones de Horacio de la época están catalogadas en Th. S. Beardsley, Hispano-classical translations printed between 1482 and 1699, Pittsburg: Duquesne University, 1970. Vid. además M. Menéndez Pelayo, Bibliografía Hispano-Latina Clásica, vol. VI, ed. E. Sánchez Reyes, Madrid: CSIC, 1951 (=Horacio en España, vol. I. Traductores y comentaristas, Santander, 1885), A. Cascón, "Horacio y los mejores ingenios españoles: sobre la evolución y el concepto de traducir", en R. Cortés y J. C. Fernández Corte (eds.), Bimilenario de Horacio, Salamanca: Universidad, 1994, pp. 359-368, M. Rodríguez Pantoja, "Horacio en la literatura española: el papel de la traducción", Myrtia, 9 (1994) pp. 153-184. Sobre Villegas vid. V. Bocchetta, Horacio en Villegas y en Fray Luis de León, Madrid: Gredos, 1971.

4. Sobre la relación entre ambos poetas vid. J. Bravo Vega, "Esteban Manuel de Villegas: panorama histórico-literario de un escritor", Revista de Literatura, LV. 110 (1993) pp. 465-485. Bravo considera que Villegas no mantuvo una relación directa con el llamado "grupo aragonés", sino que ésta se limitaba a Bartolomé Leonardo. Dicha relación es descrita del modo siguiente: "Esteban de Villegas aceptó su magisterio, pero no desde la perspectiva de militancia en una escuela común, sino desde la común identidad con el horacianismo y con los modelos literarios que el aragonés proponía" (pp. 483 y s.).

5. M. Rodríguez Pantoja, "Traductores y traducciones", en Los humanistas españoles y el humanismo europeo, IV simposio de Filología Clásica, Murcia: Universidad, 1990, pp. 91-124, esp. 103. No es posible ofrecer datos exactos sobre la fecha de composición de ambas traducciones. Las Rimas de Bartolomé Leonardo de Argensola (1561-1631) fueron publicadas de forma póstuma en 1634. Esta traducción aparece también impresa en el Cancionero de 1628, f. 773, aunque debió ser escrita mucho antes. Las Eróticas de Villegas (1589-1669) se publicaron por primera vez en 1618, y debieron ser compuestas entre 1603 y 1617, época en que según él mismo confiesa (Eróticas V, 115 y ss.), trataba en su aprendizaje de seguir los pasos del aragonés (Sobre los problemas relativos a la edición de la obra vid. J. Bravo Vega, "Esteban Manuel de Villegas: panorama...", pp. 472 y ss.; Esteban Manuel de Villegas. La obra literaria: manuscritos e impresos, Logroño: Instituto de Estudios Riojanos, 1989, pp. 89 y ss. 
Asimismo, según Pérez González ${ }^{6}$, en la teoría de la época se tiende a considerar las traducciones como obras de arte, de modo que la relación entre la actividad traductora y literaria resulta inseparable. En el caso de Horacio, aparte de la traducción en prosa de Villén de Biedma ${ }^{7}$, sin pretensiones literarias -aunque probablemente consultada por autores posteriores, como es el caso del propio Villegas ${ }^{8}$ - ya en el Renacimiento se realizan algunas en verso de poemas sueltos, entre las que destacan las realizadas por Fray Luis de León?.

Volviendo al poeta objeto de estudio, parece ser que fue un buen conocedor de los clásicos ${ }^{10}$, a los que anotó en unas Disertaciones críticas en dos tomos ${ }^{11}$, y un asiduo traductor de Horacio, del que vertió al castellano el libro I completo de las Odas. Sin embargo, algunas valoraciones de sus traducciones horacianas, como la de Menéndez Pelayo, no resultan del todo positivas:

6. M. Pérez González, "La reflexión traductora desde la Antigüedad hasta el s. XVIII: una propuesta de interpretación", Minerva 10 (1996) pp. 107-124, esp. 116-117. Sobre la teoría de la época vid. además M. A. Vega (ed.), Textos clásicos de teoría de la traducción, Madrid: Cátedra, 1994, pp. 21 y ss., J. C. Santoyo, "Aspectos de la reflexión traductora en el Siglo de Oro español", en J. C. Santoyo, Historia de la traducción: quince apuntes, León: Universidad, 1999, pp. 71-83. J. F. Ruiz Casanova, Aproximación a una historia de la traducción en España, Madrid: Cátedra, 2000, pp. 145 y ss., E. Coseriu, "Vives y el problema de la traducción", en Tradición y novedad en la ciencia del lenguaje, Madrid: Gredos, 1977, pp. 86-102, etc.

7. Q. Horacio Flacco poeta lírico latino. Sus obras con la declaración magistral en lengua castellana. Por el Doctor Villén de Biedma, En Granada por Sebastián de Mena, 1599.

8. Del Campo, op. cit., p. 25.

9. Sobre sus traducciones de Horacio vid. Bocchetta, op. cit., V. Cristóbal, "Horacio y Fray Luis", en D. Estefanía (ed.), Horacio, el poeta y el hombre, Madrid-Santiago de Compostela: Ediciones Clásicas-Universidad de Santiago, 1994, pp, 163-189, esp. 163-4, C. A. Zorita, "Fray Luis, traductor de Horacio", en C. Morón y M. Revuelta (eds.), Fray Luis de León. Aproximaciones a su vida y a su obra, Santander: Sociedad Menéndez Pelayo, 1989, pp. 281-310, E. L. Rivers. "Fray Luis de León: traducción e imitación", Edad de oro IV (1985) pp. 107-115. J. F. Alcina (ed.), Fray Luis de León. Poesía, Madrid: Cátedra, 19978, pp. 38 y ss. Sobre su teoría de la traducción, aparte de las obras ya citadas vid. F. Calero, "Teoría y práctica de la traducción en fray Luis de León", Epos, VII (1991) pp. 541-558, C. Codoñer, "Fray Luis: "interpretación", traducción poética e imitatio", Criticón, 61 (1994) pp. 31-46.

10. Sobre su formación clásica vid. J. Bravo Vega, Esteban Manuel de Villegas (1589-1669). Estudio biográfico, Logroño: Instituto de Estudios Riojanos, 1989, pp. 57 y ss. Sobre su fortuna posterior y otras cuestiones vid. E. del Campo, "Villegas es el padre de la anacreóntica española", Berceo 63 (1962) pp. 189199; 65 (1962) pp. 359-370; 68 (1963) pp. 239-256, F. Yndurain, "Villegas: una revisión de su poesía", Berceo 17 (1950) pp. 697-722. J. Bravo Vega, Esteban Manuel de Villegas (1589-1669). Fortuna crítica, Logroño: Instituto de Estudios Riojanos, 1989. Sobre otras cuestiones relativas a su vida y obra vid. A Cillero, El cisne de Najerilla (Don Esteban Manuel de Villegas), Logroño: Ochoa, 1971, E. del Campo, D. Esteban Manuel de Villegas. Algunos aspectos de su vida y obra, Logroño: Instituto de Estudios Riojanos, 1972.

11. Sobre el hallazgo entre los fondos de la Biblioteca Nacional de dichos comentarios vid. J. Bravo Vega, Esteban Manuel de Villegas. La obra literaria: manuscritos e impresos..., pp. 39 y ss., 161 y ss.; "El tomo II de las Disertaciones críticas de Esteban Manuel de Villegas", Melanges de la Casa de Velázquez, 27. 2 (1991) pp. 181-197. En la actualidad el prof. E. del Río Sanz dirige un proyecto titulado "Humanismo, filología y literatura en el siglo XVII español: estudio y edición crítica de las Dissertationes criticae de Esteban Manuel de Villegas" (PB 98- 0196), que dará nuevas luces sobre el tema. 
No era dócil ni flexible la pluma del poeta najerano; no acertaba a reproducir la concisión ni el aticismo de su modelo, y torciose casi siempre a largas perífrasis, incurriendo a la continua en monstruosas aberraciones. ${ }^{12}$

En esta línea Alonso Cortés en su edición del poeta, que es la aquí utilizada, las considera obras de juventud influidas por la estética de su admirado Bartolomé Leonardo:

No tan afortunado fue Villegas en las traducciones de Horacio, aunque los defectos más sean imputables al estilista que al traductor. Villegas veía a Horacio a través de Bartolomé Leonardo de Argensola, de quien era gran admirador, y dejábase llevar a la vez del gusto reinante, cuyo contagio difícilmente hubiera podido evitar un mozo de veintitantos años. ${ }^{13}$

Alonso Cortés centra los defectos de las traducciones de Villegas en cuestiones de estilo, al mismo tiempo que señala su vinculación con la estética argensolista. Sin embargo, el marco de una introducción no permite realizar un examen exhaustivo de la relación entre las técnicas de traducción de ambos poetas ${ }^{14}$, tarea que va a constituir el objetivo del presente estudio, centrado en su versión de Hor. Carm. I $35^{15}$. Para facilitar el seguimiento del mismo y posibilitar al lector obtener sus propias conclusiones, se ofrecen junto a ésta el texto original latino y la traducción argensolista ${ }^{16}$ :

12. Menéndez Pelayo, op. cit. pp. 95 y s. Un estado de la cuestión puede verse en Del Campo, op. cit., pp. 21 y ss.

13. Esteban Manuel de Villegas, Eróticas o amatorias, ed. de N. Alonso Cortés. Madrid: EspasaCalpe, 1969 [1913], p. XXII.

14. Análisis de este tipo han sido realizados en trabajos como el de Boccheta, donde las traducciones de Villegas se comparan con las de Fray Luis. Según Bocchetta, op. cit. p. 132 Villegas conocía algunas versiones luisianas, como la segunda de la oda a Mecenas.

15. La terminología ha sido escogida según criterios eminentemente prácticos, y se utilizan conceptos tradicionales en este tipo de estudios, como los de "amplificación" o "abreviación". Cuando ha sido necesario introducir términos más específicos se ha seguido a E. Torre, Teoría de la traducción literaria, Madrid: Síntesis, 1994, pp. 121-139.

16. Las ediciones utilizadas para Horacio y Argensola son las siguientes:, Q. Horati Flacci Opera, ed. de D. R. Schackleton-Bailey, Stuttgart: Teubner, 1985, Bartolomé Leonardo de Argensola, Rimas, (2 vols.), ed. de J. M. Blecua. Madrid: Espasa-Calpe, 1974. Asimismo, se ha consultado Rimas de Lupercio y Bartolomé Leonardo de Argensola, (2 vols.), ed. de J. M. Blecua. Zaragoza: CSIC, 1950-1951, con aparato crítico. 


\begin{tabular}{|c|c|c|}
\hline Texto de Horacio & Traducción de Argensola & Traducción de Villegas \\
\hline $\begin{array}{l}\text { O diva, gratum quae regis Antium, } \\
\text { praesens vel imo tollere de gradu } \\
\text { mortale corpus vel superbos } \\
\text { vertere funeribus triumphos, }\end{array}$ & $\begin{array}{l}\text { Oh diosa, tú que riges } \\
\text { el agradable Ancio, y nuestros fines } \\
\text { a tu gusto diriges, } \\
\text { ya desde el centro al sol los avecines, } \\
\text { o ya las trïunfales } \\
\text { pompas quieras trocar en funerales; }\end{array}$ & $\begin{array}{l}\text { ¡Oh tú divina diosa, } \\
\text { queriges la ciudad deAncio agradable, } \\
\text { Fortuna, poderosa } \\
\text { para subir de estado miserable } \\
\text { la humana criatura! } \\
\text { ¡Tú, que para los triunfos opulentos } \\
\text { abres la más horrible sepultura! }\end{array}$ \\
\hline $\begin{array}{l}\text { te pauper ambit sollicita prece } \\
\text { ruris colonus, te dominam aequoris } \\
\text { quicumque Bithina lacessit } \\
\text { Carpathium pelagus carina. }\end{array}$ & $\begin{array}{l}\text { a ti el labrador pobre } \\
\text { con solícitos ruegos te procura, } \\
\text { y el que su nave sobre } \\
\text { el Carpacio piélago aventura, } \\
\text { de las ondas, señora, } \\
\text { a ti, en partiendo de Bitinia, adora. }\end{array}$ & $\begin{array}{l}\text { El mísero que labra } \\
\text { terreno inculto, a ti te solicita } \\
\text { con devota palabra; } \\
\text { y el otro que el Carpacio facilita } \\
\text { con bitinio navío, } \\
\text { a ti sola te nombra y atribuye } \\
\text { de todo el mar el ancho señorío. }\end{array}$ \\
\hline $\begin{array}{l}\text { te Dacus asper, te profugi Scythae, } \\
\text { urbesque gentesque et Latium ferox } \\
\text { regumque matres barbarorum et } \\
\text { purpurei metuunt tyranni, }\end{array}$ & $\begin{array}{l}\text { A ti el áspero dacio, } \\
\text { los fugitivos scitas y otras gentes } \\
\text { temen, y el fértil Lacio, } \\
\text { madres de reyes bárbaros ausentes, } \\
\text { los tiranos temidos, } \\
\text { bien que de rica púrpura vestidos. }\end{array}$ & $\begin{array}{l}\text { A ti, pues, repugnante } \\
\text { temen elde Valaquia, ásperoen guerra, } \\
\text { y el Cita siempre errante, } \\
\text { y todas las naciones de la tierra, } \\
\text { y el fiero Italiano, } \\
\text { y las madres de bárbaros monarcas, } \\
\text { y, vestido de púrpura, el tirano, }\end{array}$ \\
\hline $\begin{array}{l}\text { iniurioso ne pede proruas } \\
\text { stantem columnam, neu / } \\
\text { populus frequens } \\
\text { ad arma cessantis, ad arma } \\
\text { concitet imperiumque frangat. }\end{array}$ & $\begin{array}{l}\text { No con el pie injurioso } \\
\text { esta columna firme postrar quieras, } \\
\text { ni el vulgo en sedicioso } \\
\text { tumulto al pueblo délas armas fieras, } \\
\text { y el que cesaba vuelva } \\
\text { a armarse, y el imperio se resuelva. }\end{array}$ & $\begin{array}{l}\text { porque con pie de injuria } \\
\text { no postres su columna levantada, } \\
\text { ni el pueblo en civil furia } \\
\text { mueva a rabia a la gente sosegada, } \\
\text { y "¡alarma, alarma!" diga, } \\
\text { y estrague sus imperios juntamente. } \\
\text { con mano ensangrentada y enemiga. }\end{array}$ \\
\hline $\begin{array}{l}\text { te semper anteit saeva Necessitas, } \\
\text { clavos trabalis et cuneos manu } \\
\text { gestans aena, nec severus } \\
\text { uncus abest liquidumque plumbum. }\end{array}$ & $\begin{array}{l}\text { En tu pompa precede } \\
\text { la gran necesidad, que en la cruel/ } \\
\text { diestra } \\
\text { los clavos, a quien cede } \\
\text { el leño duro, y otros hierros muestra; } \\
\text { ni falta el garfio agudo, } \\
\text { ni el grave plomo, de piedad desnudo. }\end{array}$ & $\begin{array}{l}\text { Siempre llevas delante } \\
\text { a la Necesidad, trayendo airada } \\
\text { su mano de diamante } \\
\text { clavos y cuños, sin que limitada } \\
\text { de sus deudos ausente } \\
\text { el garfio severísimo corvado } \\
\text { y el plomo demretido al fuego ardiente. }\end{array}$ \\
\hline $\begin{array}{l}\text { te Spes et albo rara Fides colit } \\
\text { velata panno, nec comitem abnegat, } \\
\text { utcumque mutata potentis } \\
\text { veste domos inimica linquis. }\end{array}$ & $\begin{array}{l}\text { Hónrate la esperanza, } \\
\text { la rara fe, de un blanco velo toda } \\
\text { cubierta, a quien mudanza } \\
\text { jamas de tu amistad desacomoda, } \\
\text { aun cuando te declaras } \\
\text { y los soberbios techos desamparas. }\end{array}$ & $\begin{array}{l}\text { También te reverencia } \\
\text { la Esperanza y la Fe de algunos rara, } \\
\text { cubierta su presencia } \\
\text { deunblanco velodesdeel piea ala cara; } \\
\text { ni niega el serte amiga, } \\
\text { aunque, mudada tú la vestidura, } \\
\text { huyas el regio alcázar enemiga. }\end{array}$ \\
\hline
\end{tabular}


at vulgus infidum et meretrix, retro periura cedit, diffugiunt cadis cum faece siccatis amici ferre iugum pariter dolosi.
El vulgo fraudolento, la ramera perjura apenas mira el común detrimento que el pie poco constante atrás retira, y en el trance postrero rehuye la cerviz del yugo fiero.

serves iturum Caesarem in ultimos orbis Britannos et iuvenum recens examen Eois timendum partibus Oceanoque rubro.

heu heu, cicatricum et sceleris pudet fratrumque. quid nos dura refugimus aetas? quid intactum nefasti liquimus? unde manum iuventus

metu deorum continuit? quibus pepercit aris? o utinam nova incude diffingas retusum in Massagetas Arabasque ferrum!

(Carm. I 35)
A Cesar, que a dar guerra va a los britanos últimos del mundo, y al escuadrón que atierra los reinos del Aurora, y del profundo Océano, te ruego que nos lo restituyas con sosiego.

Mas, ique grande vergüenza!: ¿las heridas no son de los hermanos? ¡Qué infame desvergüenza!

¿Libre pudo pasar por nuestras / manos?

¡Qué maldad inventada, a atrevimiento ajeno reservada!

¿A quien detuvo el miedo

de Dios, que perdonase algunas aras? ¿Cuál hierro estuvo quedo?

Oh tú, que en nuevo yunque lo/ preparas,

a los árabes dañe y masagetas

[Rimas195]
Pero el vulgo inconstante, y la ramera pésima y perjura atrás vuelve al instante que ve vuelta del otro la ventura, y los falsos amigos, viendo secas al cántaro las heces, huyen de ser a tanto mal testigos.

Yo agora a ti te ruego que al César, que a los últimos/ Britanos

ha de partirse luego, quieras guardarle de sus fieras manos, y a su escuadrón, temido allá en las partes del indiano oriente y en el golfo de púrpura teñido.

iAy, cuanto infama veros llenos de cicatrices, oh romanos, por vuestros brazos fieros!

¡Y, ay, cuánto ofende ver que / siendo hermanos hagáis tan impíos hechos y a tal rigor os entreguéis, volviendo las propias armas a los propios / pechos!

¿Mas, oh, por cierto dura edad! Pregunto: ¿a qué infernal /pecado

huyó nuestra locura?

¿Qué atrocidades no hemos /intentado?

¿Cuándo el mancebo fiero, por medio de los dioses soberanos, dejó los robos o soltó el acero?

¿A qué piadosas aras han perdonado nuestras manos fieras, cudiciosas y avaras?

¡Ojalá tú, Fortuna, agora quieras a sus estoques botos

volver a darles en tu yunque filos contra los Citas y Arabes remotos!

(Eróticas, $1^{a}$ parte, libro II, versión 35) 
La primera diferencia que se observa en la traducción de Villegas respecto a la de Argensola se halla en la forma métrica elegida para verter las estrofas alcaicas del original, pues éste utiliza estrofas aliradas de siete versos ${ }^{17}$, mientras que el aragonés es más tradicional al emplear el sexteto-lira ${ }^{18}$. Así pues, en Villegas la tendencia a la amplificación será mucho más marcada que en su predecesor, ya que utiliza estrofas con mayor número de versos ${ }^{19}$.

Una vez establecida esta caracterización de la métrica, se pasará a comentar en detalle la relación existente entre cada estrofa latina y sus versiones en Argensola y en Villegas, con el fin de conocer en qué medida los diversos elementos lingüísticos del original corresponden con los de la traducción y qué tipo de variaciones se producen cuando dicha correspondencia no se da. Empezando por la primera estrofa, se observa que Villegas, del mismo modo que Argensola, trata de mostrarse fiel al original latino en su inicio. Esta literalidad en los comienzos es un rasgo habitual de las traducciones de la época y su función consiste en facilitar al lector el reconocimiento de la fuente ${ }^{20}$. Por otra parte, el "Oh diosa" de Bartolomé Leonardo resulta más cercano a la concisión del latín que el "Oh tu divina diosa" de Villegas, con la aplicación a "diosa" del epíteto "divina", que resulta redundante, aunque traduce de forma etimológica el diva del original, y la adición del pronombre "tu". Éste también aparece en la versión de Argensola, aunque con una función diferente, pues es el antecedente de la relativa que aparece a continuación. El resto del primer verso latino es traducido de forma casi literal en el segundo verso de Villegas, salvo por la adición explicativa del sustantivo "ciudad" del que depende el complemento nominal "de Ancio", que traduce el complemento directo Antium ${ }^{21}$. En este punto difiere esta versión de la de Argensola, en la que estas adiciones son menos frecuentes. Sin embargo, ambos poetas coinciden en traducir regis por riges, según la etimología, coincidencia que no implica una relación entre ambos textos, ya que es una forma habitual de traducir el término ${ }^{22}$.

17. Sobre la métrica de Villegas vid. A. García Calvo, "Unas notas sobre la adaptación de los metros clásicos, por D. Esteban Manuel de Villegas", BBMP 26 (1950) 92-105, E. del Campo, op. cit., pp. 269 y ss., Bravo, "Esteban Manuel de Villegas: panorama...", pp. 480 y ss.

18. Se trata de una combinación profusamente utilizada por Fray Luis en sus versiones horacianas. Sobre su uso en traducciones vid. T. Navarro Tomás, Métrica española, Madrid-Barcelona, 19744, p. 207.

19. La tendencia a la amplificatio es común en las traducciones de estas épocas (Rodríguez Pantoja, art. cit. p. 116).

20. Según R. Herrera Montero, La lírica de Horacio en Fernando de Herrera, Sevilla: Universidad, 1998, p. 25, este rasgo se da también en Fernando de Herrera. Sobre las versiones herrerianas vid. además R. Navarro Durán, "La oda Diffugere nives de Horacio, traducida por Fernando de Herrera", Boletín de la Real Academia española, LXVII 225 (1982) pp. 499-541. Ma. I. Osuna, "La oda IV, 10 de Horacio traducida por Fernando de Herrera (con un preámbulo sobre las traducciones horacianas en los comentaristas de Gracilaso)", Archivo Hispalense LXXV (1992) pp. 83-93.

21. Villén de Biedma también recurre a la adición explicativa al traducir "la ciudad agradable de Antia".

22. En el diccionario de A. de Nebrija, Dictionarium..., Compluti, in officina, Arnaldi Guillelmi de Brocario, 1520. s.v. rego aparecen las acepciones 'regir', 'gobernar'. 
A partir de aquí se dan mayores libertades en ambas versiones, aunque Villegas, salvo en algunos detalles, ha tratado de mantenerse más fiel al original. En lo que se refiere a la estructura sintáctica, los versos 3-4 del texto latino presentan como elemento principal el participio praesens, concertado con el vocativo o diva, y del que dependen los infinitivos tollere y vertere coordinados mediante la correlación vel...vel. Argensola traduce los tres elementos verbales por formas personales, coordinando la primera con el verbo "riges" de la relativa, y uniendo las dos siguientes mediante una correlación "ya...ya", equivalente a la que une los infinitivos latinos. Villegas, por su parte, conserva de forma más exacta la estructura del sintagma formado por el participio y el primer infinitivo, mientras que el segundo se convierte en una forma personal independiente. El participio se traduce mediante el adjetivo "poderosa", que en este caso se hace depender de un "Fortuna" añadido, y que no está presente en Argensola. El infinitivo tollere se traduce por "para subir", construcción final que corresponde a éste sintáctica y semánticamente. En la traducción de los complementos imo...de gradu por "de estado miserable" y mortale corpus por "humana criatura" se observa modulación semántica ${ }^{23}$, con paso de lo concreto a lo abstracto en el primer caso y disolución de la metonimia en el segundo. Argensola introduce mayores variaciones en el plano léxico-semántico que Villegas, pues praesens se traduce por la construcción amplificada "a tu gusto diriges", tollo por "avecinar" y su complemento imo...de gradu por dos circunstanciales que expresan el origen y término del movimiento: "desde el centro al sol", etc. Asimismo se anticipa la traducción de mortale corpus por "nuestros fines" al verso anterior y se hace depender directamente de "diriges". En la traducción del segundo infinitivo, Villegas recurre a la variatio, y lo introduce como forma personal en una oración relativa dependiente del vocativo "tú", creando una estructura paralela a los dos primeros versos de la estrofa. En este caso, se dan mayores libertades en la traducción de los elementos concretos. El verbo "abres" presenta una semántica diferente al vertere latino, frente a la perífrasis "quieras trocar" elegida por Argensola. Asimismo los complementos superbos... triunfos y funeribus sufren transposición sintáctica ${ }^{24}$ en Villegas, invirtiendo sus funciones originales al convertirse el primero en el circunstancial de finalidad "para los triunfos opulentos", y el segundo en el complemento directo "la más horrible sepultura", con adición del adverbio y el adjetivo y modulación de lo abstracto a lo concreto.

23. La modulación es definida por Torre, op. cit., p. 128 como introducción de un cambio en las categorías de pensamiento o establecimiento de un diferente punto de vista para enfocar la realidad extralingüística. La modulación puede afectar a distintos planos lingüísticos, como la sintaxis o la semántica. Vid. además M. A. Coronel Ramos, "La modulación como método traductorio de Vicente Mariner. El caso de su traducción latina de Ausiàs March", en A. $\mathrm{M}^{\mathrm{a}}$ Aldama, et. al. (eds.), De Roma al siglo XX, (2 vols.), Madrid: SELat- UNED-Universidad de Extremadura, 1996, II, pp. 677-687.

24. Torre, op. cit., p. 127 define la transposición como un cambio en el plano morfosintáctico, que apenas afecta a la perspectiva semántica o al punto de vista desde el que se enfoca la realidad extralingüística. Sin embargo advierte que en la práctica la frontera entre este procedimiento y la modulación resulta difícil de trazar. 
La estructura de la segunda estrofa se basa en el paralelismo, con dos oraciones yuxtapuestas que comparten el verbo ambit, sólo expresado en la primera de ellas, y un complemento te en anáfora, estructura que los traductores han tratado de conservar en la medida de lo posible. Argensola trata de preservar en mayor medida la literalidad en la parte inicial que Villegas, pues este último traduce el sintagma pauper.../ ruris colonus de forma amplificada por "El mísero que labra terreno inculto", frente al conciso "labrador pobre" del aragonés. En cuanto al léxico, destaca la traducción de sollicita prece por "devota palabra", donde Villegas no utiliza la forma etimológica del adjetivo como su predecesor, sino que lo hace en el verbo "solicita", traducción de ambit. La traducción de prece por "palabra" implica reducción semántica ${ }^{25}$, frente al "ruegos" de Argensola.

En la segunda parte de la estrofa las libertades son mayores en ambos autores. Villegas amplifica el te dominam aequoris, traducido en los dos versos finales por "a ti sola te nombra y atribuye/ de todo el ancho mar el señorío", frente al "de las ondas, señora" de Argensola, que dependería de un verbo "adora", traducción del ambit sobreentendido. Sin embargo, en la traducción de la oración introducida por quicumque, Villegas respeta en mayor medida la sintaxis del original, pues Carpathium pelagus sigue siendo complemento directo, frente al "sobre/ el Carpacio piélago" de Argensola, aunque suprime pelagus y sustantiva el adjetivo. Asimismo, el ablativo Bithina.......carina se traduce por "bitinio navío", donde sólo hay que destacar la eliminación de la metonimia, frente a la transposición y desdoblamiento que se produce en Argensola, donde carina se convierte en el complemento directo "nave", y el adjetivo en la construcción "en partiendo de Bitinia".

La sintaxis de la tercera estrofa es respetada en mayor o menor medida en ambas versiones. Sin embargo, se encuentran variaciones en la traducción de algunos elementos, con una mayor tendencia en Villegas a la adición, como la del adjetivo "repugnante", la del sintagma "en guerra", aplicado al adjetivo "áspero", cuya función es explicativa respecto al mismo, el adverbio "siempre", o el adjetivo "todas". Este recurso fue también utilizado por Argensola, que añade los términos "ausentes", "temidos" o "rica". Existen otros recursos más complejos, como la traducción por adaptación cultural de Dacus por "al de Valaquia" que vemos en Villegas, pero no en Argensola ${ }^{26}$. Algo similar se observa en la de Latium ferox por "fiero italiano",

25. El procedimiento comentado entraría dentro de lo que Coronel, art. cit. p. 678, denomina 'modulación difuminadora', en la cual se produce una reducción del contenido del original.

26. Según Cascón, art. cit. p. 368, o M. Jiménez San Cristóbal, "Una traducción inédita del Ibam forte via Sacra... en el s. XVIII: Vicente Alcoverro, traductor de Horacio", CFC (Est.Lat.), 17 (1999) pp. 259-278, esp. 264, se trata de un rasgo propio de Fray Luis de León cuya finalidad consiste en facilitar la comprensión del texto. 
que Argensola traduce por "fértil Lacio"27. En cuanto a urbem gentesque, ambos poetas establecen modificaciones en las que se sustituyen los dos sustantivos coordinados por un solo sintagma. Villegas utiliza la paráfrasis "todas las naciones de la tierra"28, mientras que Argensola prefiere conservar la etimología en "gentes", eliminar urbes y añadir el adjetivo "otras". Para concluir, en los dos poetas el adjetivo purpurei aplicado a tyranni se traduce por medio de paráfrasis explicativa, aunque Villegas utiliza la expresión "vestido de púrpura", más concisa que el "bien que de rica púrpura vestidos", con valor concesivo ausente en el original.

En la estrofa siguiente, como viene siendo habitual, la parte inicial se traduce de forma más literal que el resto. La correspondencia entre elementos es casi exacta en ambos poetas castellanos salvo en pequeños detalles. Argensola, por ejemplo, utiliza la forma perifrástica "postrar quieras" por frangas. Villegas, por su parte, traduce el ne por "porque...no", conservando la subordinación presente en el original, frente a Argensola, que prefiere dividir el periodo sintáctico en dos. Por otro lado, el riojano convierte por transposición el adjetivo iniurioso en el sintagma preposicional "de injuria", probablemente con la finalidad de que rime con "furia".

Mayores libertades se observan más adelante, con una marcada tendencia a la amplificación, pues la oración ...neu populus frequens/ ad arma cessantis, ad arma concitet... en ambos casos queda desdoblada. Sin embargo, Villegas se muestra más fiel al original, pues en la primera de ellas el verbo "mueva a rabia", a pesar de la incrementación léxico-semántica ${ }^{29}$, recoge en cierta medida el significado de concitet, mientras que esto no sucede ni en "dé" ni en "vuelva a armarse" de Argensola. Existe alguna coincidencia entre ambos poetas, como la que se da respecto al participio frequens, traducido mediante un sintagma introducido por "en" y compuesto

27. Villén de Biedma traduce el término por "feroz". La traducción de ferox por "fertil" del texto argensolista pudo ser debida a una confusión con ferax, debida a un fallo en una posible trascripción del texto llevada a cabo por el poeta, o a una variante en la edición manejada. A pesar de haber consultado varias ediciones de la época, el texto no ha podido ser descubierto. Por otra parte, el propio texto argensolista presenta problemas textuales, ya que en el manuscrito llamado A por FoulchéDelbosc y en el 10330 del British Museum aparece la variante "fuerte", que tal vez tradujera el ferox latino. Ya que no se conoce la datación exacta de estos manuscritos cualquier hipótesis al respecto resultaría arriesgada, aunque es posible que Argensola o alguno de sus copistas revisase la traducción basándose en la variante habitual del texto de Horacio, mientras la primera versión, recogida en la edición de 1634 de Argensola, así como en las actuales, circulaba de forma simultánea. Sobre la transmisión del texto de Argensola vid. R. Foulché-Delbosc, "Pour une édition des Argensolas", Revue Hispanique XLVIII (1920) pp. 317-496, Blecua, Rimas de Lupercio y Bartolomé..., vol. I, pp. LX y ss.

28. La traducción de gentes por 'nación' aparece recogida en el diccionario de Nebrija, s.v. gens, donde se da la acepción 'todas las gentes de una nación', es decir, que aquí también se utiliza una paráfrasis.

29. Sobre la modulación léxica y semántica vid. Coronel, art. cit., pp. 697 y ss. 
por un sustantivo y un adjetivo: "en sedicioso Tumulto" en Argensola y " en civil furia" en Villegas ${ }^{30}$. Sin embargo, en el resto se producen multitud de discrepancias, con un mayor respeto en Villegas por el original. Por ejemplo, cessantis se traduce dentro de la primera oración por "a la gente sosegada", con la misma función que en latín, mientras que Argensola lo convierte por transposición en sujeto de la segunda oración, cuyo verbo "vuelva a armarse" recoge en mayor medida la semántica de ad arma que la del verbo concitet. En cuanto al sintagma duplicado ad arma, mientras que Argensola lo representa en las dos oraciones, Villegas lo sitúa en la segunda, en una interjección "¡alarma, alarma!" con adaptación cultural ${ }^{31}$. Finalmente la frase imperiumque frangat en Argensola se convierte en una construcción reflexiva "y el imperio se resuelva", en la que, aparte de esa forma de modulación, apenas se producen modificaciones respecto al original, frente a lo que sucede en Villegas, que lo amplifica del modo siguiente: "Y estrague sus imperios juntamente / con mano ensangrentada y enemiga", de modo que en este caso es el riojano quien se permite mayores libertades.

En la quinta estrofa, Villegas traduce el primer verso mediante transposición sintáctica, al convertir te en sujeto y Necesitas en complemento directo. Por lo demás, no introduce adiciones como las que se producen en Argensola de "en tu pompa" o "gran", aunque, como su precedesor, pospone la traducción del adjetivo saeva, y lo aplica a manu, mientras que en Horacio modifica a Necesitas. Por otra parte, Villegas respeta en mayor medida la sintaxis del original al traducir el participio del que depende, convertido en un gerundio, mientras que Argensola lo transforma en un verbo en forma personal "muestra", con una semántica diferente al gestans latino. Villegas suprime el adjetivo trabalis, amplificado por Argensola en "a quien cede el leño duro", perífrasis explicativa. Traduce cuneos por "cuñas", más literal que el argensolista "otros hierros". Aena, suprimido en Argensola, aquí se convierte en "de diamante" con adaptación cultural, pues en su época esta piedra preciosa simboliza proverbialmente la dureza en lugar del bronce de los antiguos. Para concluir, la frase final es traducida por Villegas de forma parafrástica, con multitud de adiciones, aunque desde el punto de vista del significado se acerque en mayor medida al original, ya que Argensola traduce el adjetivo liquidum aplicado a plumbum por "grave", lo que, unido a la adición de "de piedad desnudo", incluye una valoración moral que no está presente ni en Horacio ni en la traducción de Villegas.

30. Villén de Biedma traduce el participio por "convocado a campana tañida".

31. La misma traducción aparece en Villén de Biedma, op. cit. 
En la sexta estrofa se observa de nuevo que en su comienzo las traducciones se acomodan en mayor medida al texto latino que en el resto, aunque se dan algunos cambios. Destacan en Villegas las adiciones de "de algunos", "su presencia", y "desde el pie a la cara". La primera de ellas tal vez pudiera deberse al contexto religioso de la época, en el que no resultaría aceptable utilizar el epíteto rara aplicado a la fe de forma general, por lo que el poeta debe acudir a esa restricción. Respecto al "desde el pie a la cara" , Argensola había añadido en su propia versión el adjetivo "toda", aplicado a "cubierta". En ese sentido, resulta posible que Villegas realizase una amplificación de carácter explicativo del "toda" de su predecesor. El resto de la estrofa aparece traducido de forma más concisa y menos parafrástica por Villegas que por Argensola, aunque es preciso destacar en el primero la adaptación cultural de potentis.......domos, traducido como "regio alcázar". Por lo demás, Villegas respeta la correspondencia de los elementos de su traducción con los del original.

En la séptima estrofa Villegas se ciñe en mayor medida al original que su predecesor. Por ejemplo, frente al aragonés, no suprime la partícula at inicial, y traduce de forma relativamente exacta la escena final, con la alusión al cántaro y las heces, en lugar de sustituirlos por elementos de contenido diferente ${ }^{32}$. De todos modos también introduce elementos propios, como el desdoblamiento del término periura en "pésima y perjura"33, con aliteración de p, las adiciones de "al instante", "que ve vuelta del otro la ventura" o "viendo", o la sustitución de ferre iugum por "ser a tanto mal testigos".

Pasando a la estrofa siguiente, Villegas respeta en mayor medida el orden de palabras del original, pues sitúa el verbo en el primer verso, mientras que Argensola lo traslada al final. En ambos casos el subjuntivo latino se convierte en una construcción introducida por "te ruego que", aunque en Villegas la semántica de serves queda mejor plasmada, ya que se traduce como "quieras guardarle de sus fieras manos", frente al "nos lo restituyas con sosiego" de Argensola. En cuanto a los elementos dependientes de serves, en Villegas destaca la adición del adverbio "agora", cuya

32. Sobre la traducción de este pasaje J. de Burgos, Las poesías de Horacio traducidas en versos castellanos con notas y observaciones críticas por D. Javier de Burgos, I, 1820, Madrid, p. 181 y s., dice lo siguiente: "El lector a quien no contente esta versión podrá reflexionar para disculparla, que la baja imagen de los toneles apurados hasta la hez, junto a la metáfora de llevar el yugo, forman un periodo embrollado, que es casi imposible traducir con exactitud. Yo he suprimido como Argensola, y por los motivos que aporté en el prólogo, la primera imagen".

33. La traducción de un solo término desdoblado en sinónimos o cuasisinónimos era habitual en el Renacimiento y el Barroco. Sobre este procedimiento vid. G. Morocho Gayo, "Diego Gracián y sus versiones de clásicos griegos", en J. C. Santoyo et al. (eds.), Fidus interpres: Actas de las Primeras jornadas Nacionales de Historia de la Traducción, vol. II, León: Universidad, 1989, pp. 353-363, esp. 357 y s., D. Castro de Castro, "La traducción de los escolios a los idilios de Teócrito de Vicente Mariner: Algunas consideraciones", Myrtia, 11 (1996) pp.71-85, esp. 81 y ss. 
función tal vez podría ser la de expresar la idea de inmediatez del sentido yusivo del verbo ${ }^{34}$, y la omisión de orbis. En cuanto a la adición de "luego", su función consiste en marcar la idea de futuro propia del participio iturum. Otro hecho destacable es la utilización del artículo en "al César" (Augusto), ausente de la traducción de Argensola. Pasando a otra cuestión, ambos poetas coinciden en traducir de forma abreviada el sintagma iuvenum recens/ examen por "escuadrón". En cuanto a los sintagmas Eois.../ partibus Oceanoque rubro Villegas recurre a la traducción explicativa al sustituir Eois por "indiano oriente" mientras que Argensola conserva la onomástica original en "la aurora". Sin embargo, Oceano rubro aparece como "golfo de púrpura teñido", frente a Argensola que introduce una modulación de lo particular a lo general al hablar del "profundo/ océano".

En la traducción de las dos últimas estrofas, que constituyen en Horacio una unidad de contenido al hallarse encabalgadas, tanto Argensola como Villegas recurren a la paráfrasis en mayor medida que en el resto del texto. Ambos eliminan el encabalgamiento, y Villegas llega incluso a traducir las dos estrofas por tres, de modo que la correspondencia habitual entre estas unidades métricas en el original y la versión castellana se rompe. De todos modos, Villegas trata de representar en su versión buena parte de los elementos del texto latino, e incluso respetaría su sintaxis en mayor medida. La estrofa 9 por ejemplo traduciría de forma muy amplificada la primera frase de su correspondiente latina. En ella pudet conserva su función, aunque desdoblada en los verbos "infama" y "ofende", frente a la opción argensolista en que se convierte en las exclamaciones "iQué grande vergüenza!" y "!Qué infame desvergüenza!", también mediante un proceso de desdoblamiento.

La estrofa 10 de Villegas traduciría desde quid nos dura... hasta metu deorum continuit, y de nuevo hay un intento de representar los elementos más importantes del original, frente a la práctica de Argensola de eliminar algunos de ellos, como la referencia a la dura aetas o a la iuventus. Por otra parte, algunos rasgos de la versión de Villegas responderían a una adaptación cultural, como la incrementación léxicosemántica de quid en "infernal pecado", o la traducción de iuventus por "mancebo". Sin embargo, en la traducción de deorum conserva, frente a Argensola, el plural del original. En este punto es preciso llamar la atención sobre la supuesta traducción de metu por "medio" que aparece en la edición utilizada, producto, o bien de una errata o bien de un problema textual que podría haberse resuelto mediante la consulta del original latino ${ }^{35}$.

34. Dicho valor yusivo aparecería además en la expresión "te ruego que".

35. Este tipo de detalles indican la necesidad de realizar nuevas ediciones de la obra de Villegas. Es preciso señalar que la última de ellas, realizada por el poeta y filólogo Narciso Alonso Cortés, y que es la aquí utilizada, data de 1913 y ha sido reeditada en sucesivas ocasiones, pero no revisada, lo que es una prueba del relativo olvido en que se ha hallado el poeta objeto de estudio hasta fechas muy recientes. 
Para concluir, la estrofa 11 de Villegas correspondería a la parte del texto latino que abarca desde quibus hasta el final, y se caracteriza por la presencia de adiciones, como las de "piadosas", "nuestras manos fieras, /cudiciosas y avaras", pero se trata de elementos que complementan a otros ya existentes, mientas que en Argensola la adición de "¿Cuál hierro estuvo quedo?" constituye un elemento independiente. Asimismo, en la exclamación de la frase final Villegas conserva el utinam inicial, traducido por "ojalá", así como el carácter desiderativo de la frase, frente al uso del imperativo en Argensola ${ }^{36}$. Finalmente, es preciso destacar en Villegas la sustitución de Massagetas por "Citas", probablemente por razones métricas.

Tras esta descripción de la versión de Villegas de la oda I 35 de Horacio se hace necesario establecer una valoración general de su relación con la de Argensola. Se ha podido observar que se trata de dos traducciones muy diferentes en cuanto a forma y estilo, aunque en ellas se respetan ciertas tendencias propias de las versiones de la época, como por ejemplo la búsqueda de una mayor literalidad al comienzo del poema, y, dentro de cada estrofa, en su parte inicial. Dentro de esta tendencia, una particularidad que comparten Villegas y Argensola consiste en la renuncia a la habitual correspondencia entre estrofa latina y estrofa castellana en la parte final del texto, constituido en latín por dos estrofas encabalgadas. Ambos poetas rompen el citado encabalgamiento, lo que les obliga a incluir elementos propios de una estrofa en la otra, y Villegas incluso traduce esas dos estrofas en tres.

Por otra parte, existen coincidencias puntuales entre ambos poetas, algunas de las cuales pueden deberse simplemente al azar o a los hábitos de traducción de determinados términos o construcciones de la época, mientras que otras podrían atribuirse a un conocimiento por parte de Villegas de la versión de Argensola. Entre dichas coincidencias, la traducción etimológica de regis por "riges" no puede atribuirse sin más a una imitación de Argensola por parte de Villegas. En cambio en la de frequens de la cuarta estrofa por los complementos "en sedicioso tumulto"/ "en civil furia" es posible una imitación más directa, ya que Villegas, más que traducir el término latino, parece calcar la expresión utilizada por su predecesor. Algo similar sucede en la quinta estrofa, donde el adjetivo saeva, que en latín acompaña a Necesitas, es aplicado en los españoles a los términos "diestra" y "mano" respectivamente, que traducen el latín manu, y en la octava, donde el sintagma iuvenum recens/ examen se traduce por un solo término en ambos autores, concretamente "escuadrón".

36. Burgos, op. cit., p. 185 comenta las traducciones de Argensola y Villegas de este pasaje, indicando que el primero, al utilizar el indicativo, no capta la idea del texto horaciano. Asimismo, opina que el hacer rimar saetas con Masagetas resulta ripioso. En cuanto a Villegas, valora más positivamente su traducción del pasaje, aunque considera inadecuada la elección del término botos aplicado a los aceros, sólo justificable porque rima con remotos. Asimismo, la adición de tu aplicado a yunques resulta un tanto extravagante ya que de ese modo las espadas debían afilarse en un supuesto yunque de la fortuna. 
Pasando a comentar las diferencias, el mayor volumen silábico de la versión de Villegas podría hacer creer que ésta es mucho más libre que la de su predecesor. Sin embargo, se trata de una impresión que es preciso matizar, pues, a lo largo del comentario se ha podido observar que Villegas tiende a reflejar en mayor medida los elementos presentes en el original que Argensola, sin apenas incluir otros que no tengan reflejo en el texto latino, libertad que sí se da en el aragonés. Asimismo, respeta en mayor medida el contenido semántico de dichos elementos. Sin embargo, para llenar ese mayor volumen silábico ha sido necesario recurrir de forma constante a la amplificación como medio de expandir elementos preexistentes. Así pues, resulta frecuente la adición de epítetos, como "repugnante" en la tercera estrofa, complementos preposicionales como el "en guerra" añadido también en la tercera estrofa al adjetivo áspero, o la traducción por medio de paráfrasis, como la que puede verse en la segunda estrofa, donde pauper.../ ruris colonus se amplifica en "El mísero que labra terreno inculto".

Por otra parte, Villegas es más propenso al uso de aquellos recursos tendentes a acercar el texto latino al lector castellano. Entre ellos destaca la amplificación por medio de elementos de carácter explicativo, como la que se da en la primera estrofa al traducirse Antium por "la ciudad de Ancio", o la traducción por adaptación cultural, con la sustitución de aquellos elementos como los nombres geográficos propios del mundo romano por sus correspondientes contemporáneos al autor. Ejemplos de ello se han visto en la tercera estrofa, donde se traduce Dacus por "al de Valaquia" y Latium ferox por "fiero italiano". Como se ha indicado anteriormente se trata de un recurso propio de las traducciones luisianas.

Dentro de esta tendencia, Villegas acude en menor número de ocasiones a la traducción etimológica, pues, mientras que Argensola traduce en la segunda estrofa sollicita prece por "solícitos ruegos", y en la tercera gentes por "gentes" Villegas prefiere "devota palabra" y "naciones" respectivamente. Sin embargo, ambos coinciden en traducir de esta forma otros términos como el regis anteriormente comentado, o el iniurioso de la cuarta estrofa, representado como "injurioso" en Argensola y "de injuria" en Villegas.

En conclusión, a través de estos comentarios se puede observar que Villegas presenta un estilo de traducción personal, influido en cuestiones de detalle por Fray Luis y Argensola, pero cuya base se halla siempre en texto latino, que transforma según su propio gusto estético, eso sí, respetando en todo momento su contenido. 
